\title{
New records of Lutra lutra Linnaeus, 1758 from Turkey
}

\author{
Servet ULUTÜRK ${ }^{*}$, Gökhan YÜRÜMEZ ${ }^{1}$
}

${ }^{1}$ Department of Biology, Faculty of Science and Art,Batman University,Batman, Turkey

\begin{abstract}
Received: 21.11 .2017
Accepted: 23.12 .2017

Available online: 25.12 .2017

Published: 29.12.2017

Abstract: Only one species, Lutra lutra (Eurasian otter) distributed in our country among the 13 species belonging to Mustelidae family represented over the World. Lutra lutra which lives at stagnant streams, brooks, creeks, river mouths and lakes, has a wide distribution in Palearctic region. By the direct and indirect observation methods between the years of 2013 and 2017, this study contributed to the knowledge of the bio-ecology and spreading areas from Ağrı, Batman, Düzce and Van provinces of Eurasian otters, involved "Near Threatened" category according to IUCN.

Keywords: Mustelidae, Palearctic, bioecology, distribution, Turkey

\section{Türkiye'den yeni Lutra lutra Linnaeus, 1758 kayıtları}

Özet: Dünyada 13 tür ile temsil edilen Mustelidae familyasına ait su samurunun bir türü Lutra lutra (Avrasya su samuru) ülkemizde bulunmaktadır. Durgun akarsularda, dere, çay, nehir ağızları ve göllerde yaşayan Lutra lutra, Palearktik bölgede geniş bir yayılış göstermektedir. 2013-2017 yılları arasında doğrudan ve dolaylı gözlem metodları ile yapılan bu çalışma ile IUCN kriterlerine göre NT (Near Threatened) kategorisinde yer alan Avrasya su samurunun ülkemizdeki dağılış alanlarına Ağrı, Batman, Düzce ve Van illerinden yeni kayıtlar eklenerek türün biyoekolojik ve dağılış sınırları bilgilerine katkı sunulmuştur.
\end{abstract}

Anahtar kelimeler: Mustelidae, Palearktik, biyoekoloji, dağıllş, Türkiye

\section{Giriş}

Memelilerin dâhil olduğu Mammalia sınıfı omurgalıların en gelişmiş sınıfıdır. Dünya üzerinde yaklaşık 4500 memeli türü bulunur. Avrupa'da 200 kadar memeli türü görülürken, ülkemiz ise tek başına yaklaşık 160' dan fazla memeli türünü barındırmaktadır (Wilson ve Reeder 2005).

Dünyada Mustelidae familyası Lutrinae alt familyasına ait 13 su samuru türü dağılış gösterirken, ülkemizde sadece bir türü (Lutra lutra Linnaeus, 1758) yayılış göstermektedir (Kurtonur ve ark. 1996, Albayrak ve ark. 1997). Palearktik bölgede yaşayan Lutra lutra (Avrasya su samuru) en geniş yayılişa sahip su samuru türüdür (Harrison ve Bates 1991, Wilson ve Reeder 2005, Kruuk 2006). Sucul ekosistemlerde besin zincirinin en üst basamağında yer alan su samurları tatlı su sistemlerinde ve kıyısal bölgelerde yaşayan yarı sucul bir türdür (Albayrak 2002, Kayaöz 2002). Ülkemizde doğal durumunu koruyan birçok akarsu ve kollarında, durgun sularda, sazlık ve bataklık alanlarda yaşadığı ifade edilmiştir (Turan 1984, Güven 2000, Albayrak 2000, Erdoğan ve ark. 2000, Alp ve Kaptanoğlu 2000, Barlas ve Yorulmaz 2000, Pamukoğlu 2002, Toyran ve Albayrak 2016).

Durgun akarsularda, dere, çay ve nehir kenarlarında, nehir ağılarında, deltalarda girişi su altında olan yuvalarda yaşayan su samurlarının besin tercihlerini balıklar (\%65-70), amfibiler (\%10-12), omurgasızlar (\%10-12), geri kalan kısminı ise memeliler, kuşlar, kuş yumurtaları ve reptiller oluşturmaktadır (Taastrom ve Jacobsen 1999, Güven 2000). Dışkılarını su dışında kalan kaya veya ağaç kütükleri üzerine ve görülebilir bir şekilde bırakırlar (Turan 1984, Demirsoy 1996).

Türkiye'den ilk kez Danford ve Alston (1877) tarafindan Tarsus'tan kaydı verilen Lutra lutra'nin ülkemizdeki biyoekolojisi ve dağılımı ile ilgili bilgiler sınırlıdır. Özkurt ve ark. (1998) Antalya Akseki'den yapmış oldukları çalışmada bu bölgedeki su samurlarının morfolojik özelliklerini belirterek türün alttür durumunun henüz netlik kazanmadığını belirtmişlerdir. Topal (2005) Elazığ ve Malatya yörelerindeki Firat Nehri havzalarında ve Keban Baraj Gölünde yapmış olduğu çalışmada su samurlarının buralarda yayılış gösterdiğini belirtmiştir. Toyran (2010) su samurları üzerine yapmış olduğu çalışmada su samurlarının Kızılırmak Nehrinin bitki örtüsü bakımından zengin ve korunaklı bölgelerinde yayılış gösterdiğini belirtmiştir.

Toyran ve Albayrak (2016) yaptıkları çalışma ile Ankara (Sarıyar Barajı), Bitlis (Merkez ve Hizan), Kırıkkale (Delice Irmağı), Kırşehir (Hirfanlı), Konya (Taşkent) ve Mardin (Midyat) olmak üzere toplam 6 yeni lokaliteden Avrasya su samurunun kaydını vermişlerdir.

Özellikle yaşadıkları su sistemlerinin sağlıklı ve temiz olduklarına dair birer indikatör görevi gören su samurları tarımsal ilaçların, evsel ve endüstriyel atıkların kirlettiği habitatlarını kaybederek büyük bir tehdit ile karşı karşıya kalmaktadırlar. Ayrıca su samurlarının bulunduğu habitat yakınlarındaki yapılaşma, avcılık, tarım alanı genişletme çalışmaları, kum ocakları, mesire alanları, ağaç kesimi gibi etkenler su samurlarının yaşam ortamlarını tahrip ederek sayılarının azalmasına neden olmaktadır. Bununla birlikte besinlerinin azalması nedeniyle balık çiftliklerine yönelen su samurları 
işletmeciler tarafından öldürülmektedir. Ayrıca yapılan barajlar da su sistemlerini zayıflatarak su samurlarını tehdit etmektedir (Albayrak 2000, Kayaöz 2002, Özdemir ve Barlas 2002).

$\mathrm{Bu}$ çalışma ile IUCN kriterlerine göre NT (Near Threatened) kategorisinde yer alan Avrasya su samurunun ülkemizdeki dağılış alanlarına yeni kayıtlar eklenerek türün biyoekolojik ve dağılış sınırları bilgilerine katkı sunulması amaçlanmaktadır.

\section{Materyal ve Metod}

2013-2017 yılları arasında Ağrı, Batman, Düzce ve Van illerinde Orman Su İşleri Bakanlığının Biyoçeşitlilik projeleri kapsamında gerçekleştirilen arazi çalışmaları sonucu su samurları tespit edilmiştir. Türlerin tespitinde doğrudan gözlemlerin yanı sıra, dışkı ayak izi gibi dolaylı gözlem yöntemleri de kullanılmıştır. Doğrudan gözlemlerde DSLR fotoğraf makinası ve fotokapan kullanılmıştır. Ayrıca Kasım 2013 tarihinde Batman Üniversitesi Merkez Kampüsü bahçesinde yakalanan su samuru gerekli sağlık kontrolleri yapıldıktan sonra uygun yaşam ortamına birakılmıştır.

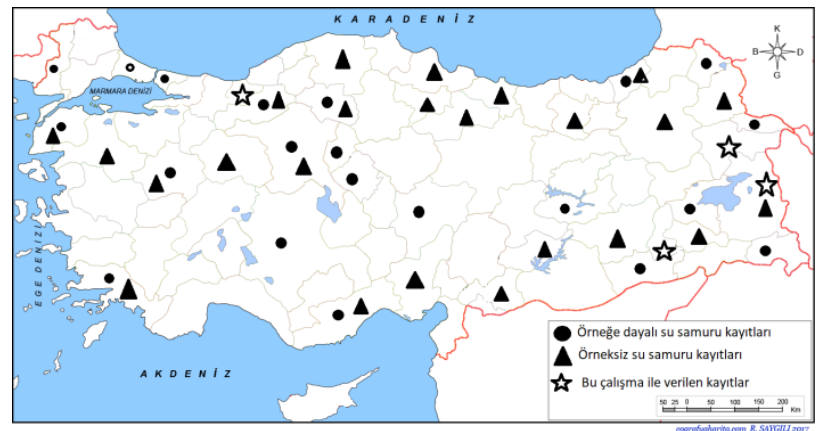

Şekil 1: Lutra lutra (Avrasya su samuru) ile ilgili daha önce verilen kayıtlar ile bu çalışma ile tespit edilen su samuru lokaliteleri

\section{Sonuçlar}

Ülkemizde dağılış sınırları daha önceki çalışmalar ile verilen su samuru ile ilgili olarak Ağrı, Batman, Düzce illerinden daha önce herhangi bir kayıt bulunmazken, Alp ve Kaptanoğlu (2000) Van'ın Çatak ilçesinde su samurlarının habitatları ve karşılaştıkları problemler ile ilgili yapmış olduğu çalışmada yöre halkının ifadeleri doğrultusunda Çatak suyunda bulunduğunu belirtmiştir. Ülkemizde bugüne kadar yapılmış çalışmalar ile 20 lokalitede örneğe dayalı kayıt verilirken, 24 lokaliteden örneksiz su samuru kayıtları verilmiştir. Bu lokalitelerden yedi tanesinde hem örnekli hem de örneksiz kayıt bulunmaktadır (Şekil 1).

2013-2017 yılları arasında yapılan arazi çalışmaları ile 4 ilde su samuru kayıtları verilmiştir (Tablo 1).

2014 yılında Ağrı'nın Diyadin ilçesinde yapılan arazi çalışmalarında yaklaşık $150 \mathrm{~m}$ uzunluğunda bir tünel oluşturan Taş köprü mevkiinde türün yaşadığ1 tespit edilmiştir. Yöre halkının mesire alanı olarak kullandığı alanda su samurları günü mağara içindeki yuvalarında geçirirken gün batımı ile birlikte tünel dışında doğrudan gözlemlenerek görüntülenmiştir. Ayrıca Van'ın Çatak ilçesinde 2014 yilında gerçekleştirilen arazi çalışmaları sırasında birey doğrudan görülmesine rağmen hızlı bir şekilde suya dalması sebebiyle fotoğrafı çekilememiştir. Ancak bölgede türe ait muhtemel yuva ve dişkı örnekleri görüntülenmiştir. Kasım 2013 tarihinde muhtemelen besin ararken yolunu şaşırarak Batman Üniversitesi Merkez Kampüsü bahçesine giren bir adet yetişkin erkek su samuru köpekler tarafından kovalanırken görevliler tarafından yakalanıp Doğa Koruma Milli Parklar Batman İl Müdürlüğüne teslim edilmiştir. Su samurunun gerekli sağlık kontrolleri yapıldıktan sonra il müdürlüğü yetkilileri ile birlikte Batman Çayında uygun yaşam ortamına bırakılmıştır (Şekil 2).

Tablo 1: 2013-2017 yılları arasında yapılan arazi çalışmaları ile tespit edilen su samurlarına ait bilgiler

\begin{tabular}{|c|c|c|c|}
\hline Lokalite & Tarih & Gözlem Tipi & Açıklama \\
\hline Ağr1 & 2014-2015 & Doğrudan & $\begin{array}{lr}\text { Diyadin } & \text { kaplicalar } \\
\text { bölgesinde } & 3 \text { birey } \\
\text { doğrudan gözlenerek } \\
\text { görüntülendi }\end{array}$ \\
\hline Batman & 2014-2015 & Doğrudan & $\begin{array}{l}\text { Merkez ilçede canlı } \\
\text { olarak yakalanan bir } \\
\text { birey dişında iki köprü } \\
\text { ve Hasankeyf ilçesinde } \\
\text { türe ait dişkı ve ayak } \\
\text { izleri bulunmuştur }\end{array}$ \\
\hline Düzce & 2015-2016 & $\begin{array}{l}\text { Fotokapan } \\
\text { Dolaylı }\end{array}$ & $\begin{array}{l}\text { Yığılca, Çilimli ve } \\
\text { Cumayeri ilçelerinde } \\
\text { türe ait izler } \\
\text { gözlemlenirken } \\
\text { Saklıkent ilçesinde tür } \\
\text { fotokapan ile } \\
\text { görüntülenmiştir. }\end{array}$ \\
\hline Van & 2016-2017 & Dolaylı & $\begin{array}{l}\text { Çatak ilçesinde tür } \\
\text { doğrudan görülmesine } \\
\text { rağmen fotoğrafı } \\
\text { çekilememiştir. }\end{array}$ \\
\hline
\end{tabular}

Yine Batman ili Hasankeyf ve İki Köprü mevkiinde 2016 yılında yapılan çalışmalar ile su samurlarına ait muhtemel yuva, dışkı ve ayak izleri görüntülenerek bu alanda türün varlığ tespit edilmiştir (Şekil 3).

Düzce ilinde Orman Su İşleri Bakanlığının Tür İzleme Projesi kapsamında yapılan arazi çalışmaları ile Saklıkent, Yığılca, Çilimli ve Cumayeri ilçelerinde yapılan doğrudan ve dolaylı gözlemler ile türe ait dışkı, ayak izi ve muhtemel yuva alanları bulunurken bu alanlarda bırakılan fotokapanlar ile su samuru görüntülenmiştir (Şekil 4).

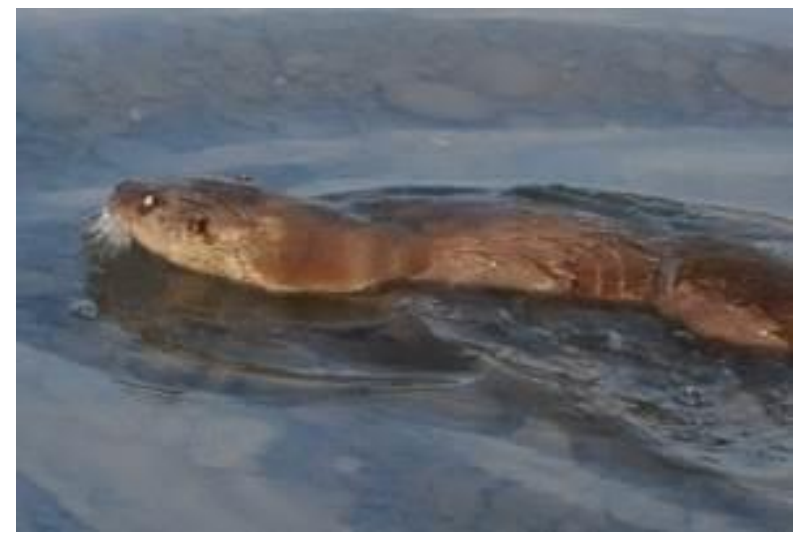

Şekil 2: Sağlık kontrolleri sonrası doğaya bırakılan Lutra lutra, Batman Çayı - Merkez 


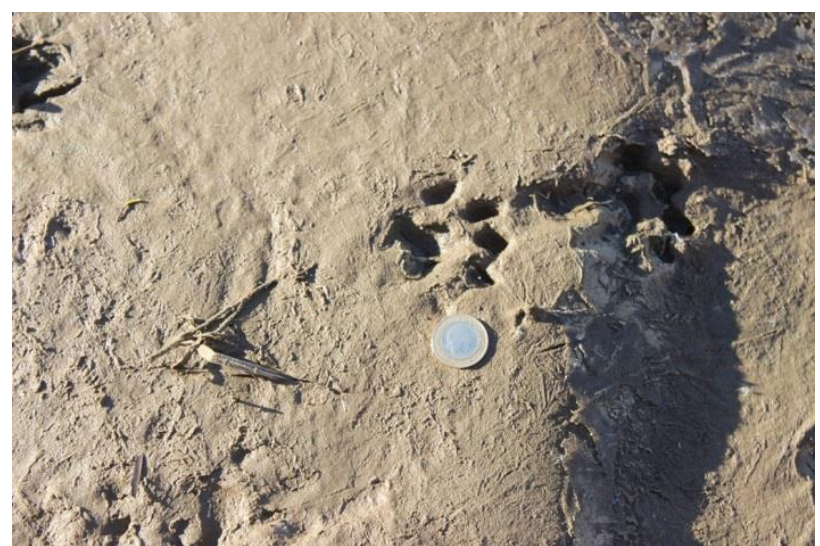

Şekil 3: Su samuru ayak izi İki Köprü mevkii, Batman

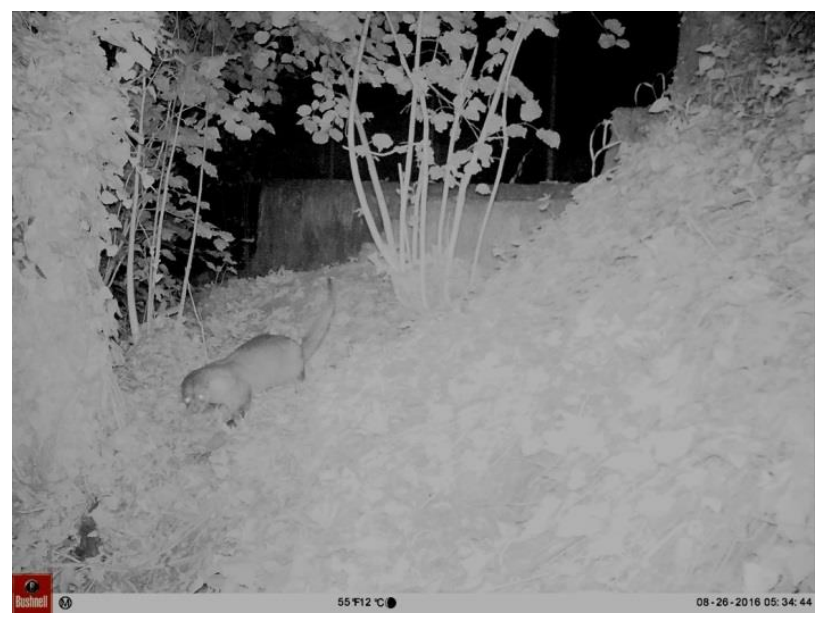

Şekil 4: Avrasya su samuruna ait fotokapan görüntüsü (Saklıkent, Düzce)

\section{Tartışma}

Biyolojik indikatör türlerden biri olan su samurları, bulundukları akarsu ve göllerin doğal yapısının korunduğunun ve sağlıklı birer habitat olduklarının göstergesidir. $\mathrm{Bu}$ nedenle türün yayılış alanlarının belirlenmesine ve korunmasına yönelik çalışmalar büyük önem kazanmaktadır. Su samurları uluslararası sözleşmelerle koruma altına alınmıştır. IUCN (Uluslararası Doğa ve Doğal kaynakları Koruma Birliği) kriterlerine göre NT (Near Threatened) kategorisinde yer alan Avrasya su samuru CITES Ek I, Bern Sözleşmesi Ek II'de listelenmiştir.

$\mathrm{Su}$ samurlarının ülkemizdeki durumları ile ilgili olarak çeşitli sempozyumlar düzenlenirken, yaşam alanları ve biyo-ekolojileri üzerine çalışmalar yapilmaktadır (Turan 1984, Güven 2000, Albayrak 2000, Erdoğan ve ark. 2000, Alp ve Kaptanoğlu 2000, Barlas ve Yorulmaz 2000, Pamukoğlu 2002, Toyran ve Yorulmaz 2016). Bu çalışma ile su samurlarının ülkemizdeki yayılış alanlarına 4 yeni kayıt eklenerek türün popülasyon bilgisine katkıda bulunulmuştur. 1998 yilının su samurunu koruma yılı olarak ilan edildiği ülkemizde yakın tehdit altında bulunan türün popülasyon yoğunluğunu olumsuz etkileyen faktörlerin başında su sistemlerinin kuruması ve kirlenmesi sebebi ile yaşam alanlarının daralması gelmektedir. Ayrıca gerek kürkü için gerekse balık çiftliklerine zarar verdikleri gerekçesiyle öldürülmeleri tür için büyük bir tehdit oluşturmaktadır. Günümüze kadar yapılan ve halen yapılmakta olan bu çalışmalar ile ülkemizde orta vadede nesli tükenme tehlikesi ile karşı karşıya kalan su samurlarının etkili bir şekilde korunabilmesi sağlanacaktır.

Bu çalışma ile su samurlarının ülkemizdeki yayılış alanlarına yeni kayıtlar eklenmiştir.

Teşekkür: Bu çalışma Orman ve Su İşleri Bakanlığı, Doğa Koruma ve Milli Parklar Genel Müdürlüğü tarafından yürütülen "Van İlinin Karasal Biyolojik Çeşitlilik ve İçsu Ekosistemleri Biyolojik Çeşitlilik ve Envanter ve İzleme Projesi", "Ağrı İlinin Karasal Biyolojik Çeşitlilik ve İçsu Ekosistemleri Biyolojik Çeşitlilik ve Envanter ve İzleme Projesi" ve "Düzce İli Flora, Damarlı Bitkiler, Fauna, Kuşlar, Memeliler, Çiftyaşarlar, Sürüngenler, İç Su Balıkları ve Habitat Ekosistem İzleme Projesi" kapsamında gerçekleştirilmiştir.

\section{Kaynaklar}

Albayrak, İ., Aşan, N., Pamukoğlu, N. 1997: Türkiye' deki Su Samurunun Durumu. Tabiat ve İnsan Dergisi, Ankara, 31 (2): 10-11.

Albayrak, İ. 2000: Türkiye'deki Su Samuru (Lutra lutra L. 1758)'nun Yayılışına Katkılar. Tabiat ve İnsan Dergisi, 34 (1): 3-7.

Albayrak, İ. 2002: Kırıkkale Kızılırmak'daki Su Samuru (Lutra lutra L. 1758) Populasyonu, (Mammalia: Carnivora) Su Samurunun Türkiye' deki Durumu. II. Sempozyum, 21-22 Eylül, Antalya.

Albayrak, İ., Toyran, K. 2008: Kırıkkale'deki Su Samuru (Lutra lutra L. 1758) Lokalitelerinin Belirlenmesi. Su Samurunun Türkiye'deki Durumu III. Sempozyum, 23-24 Ekim, Kırıkkale.

Alp, Ş., Kaptanoğlu, M. 2000: Van ili Çatak Bölgesinde Bulunan Su samurlarının Habitat ve Karşılaştığı Problemler. Tabiat ve İnsan, 34 (1): $8-10$.

Barlas, M., Yorulmaz, B. 2000: Su Samuru (Lutra lutra)'nun Muğla ve Çevresinde Yayılışı. Tabiat ve İnsan, 34 (1): 18 - 23.

Danford, C. G., Alston, E. R. 1877: On the Mammals of Asia Minor. Proceedings of the Zoological Society of London, 1: 270-282.

Erdoğan, A., Öz, M., Sert, H. 2000: Su Samuru (Lutra lutra)'nun Antalya Yöresinde ve Dünyadaki Durumu. Tabiat ve İnsan Dergisi, Ankara, 34 (1): 11-17.

Güven, N. 2000: Türkiye Su Samuru (Lutra lutra) Projesi. Tabiat ve İnsan Dergisi, Ankara, 34 (1): 32-36.

Harrison, D. L. Bates, P. J. J. 1991: The Mammals os Arabia. Harrison Zoological Museum, 1-354.

Kayaöz, E. 2002: Türkiye'deki Su Samuru (Lutra lutra L. 1758)'nun Korunmasının Önemi ve Yaşama Alanlarını Saptama Çalışmaları. Su Samurunun Türkiye'deki Durumu II. Sempozyum, 21-22 Eylül, Antalya.

Kruuk, H. 2006: Otters Ecology, Behavior and Conservation. Oxford University Press. New York. 1-265.

Kurtonur. C., Albayrak. İ., Kıvanç. E., Kefelioğlu. H., Özkan. B. 1996: Türkiye Omurgalılar Tür Listesi; Memeliler (Mammalia). DPT/TBAGÇev. Sek., Nurol Matb., Ankara, 1-23.

Özdemir, N., Barlas, M. 2002: Muğla İlindeki Mevcut Alabalık İşletmelerinde Su Samurları Konusunda Yapılan Bilinçlendirme ve Eğitim Çalışmaları. Su Samurunun Türkiye'deki Durumu II. Sempozyum, 21-22 Eylül, Antalya.

Özkurt, Ş., Sözen, M., Yiğit, N., Çolak, E. 1998: Notes on Distributional Records and Some Characteristics of Five Carnivore Species (Mammalia: Carnivora) in Turkey. Turkey Journal of Zoology, 25: 285288.

Pamukoğlu, N. 2002: Kayseri Kızılırmak Su Samuru (Lutra lutra L. 1758) Populasyonunun Bazı Ekolojik Özellikleri. Su Samurunun Türkiye'deki Durumu II. Sempozyum, 21-22 Eylül, Antalya.

Taastrom, H. M., Jacobsen, L. 1999: The Diet of Otters (Lutra lutra L.) in Danish Freshwater Habitats: Comparisons of Prey Fish Populations. Journal of Zoology, 248: 1-13. 
Toyran, K. 2010: Kırıkkale Kızılırmak Su Samuru, Lutra lutra (Linnaeus,

1758) Yayılış Alanlarının Belirlenmesi. Doktora Tezi, Kırıkkale Üniversitesi, Fen Bilimleri Enstitüsü.

Toyran, K., Albayrak, T. 2016: Avrasya Su Samuru, Lutra lutra (Linnaeus, 1758)'nın Türkiye'deki Yayılış Kayıtları. Süleyman Demirel Üniversitesi Fen Bilimleri Enstitüsü Dergisi, 20 (3): 575-578.

Turan, N. 1984: Türkiye'nin Av ve Yaban Hayatı Hayvanları Memeliler. Olgun Kardeşler Matbaacılık Sanayi, Türkiye.

Wilson, D. E., Reeder. D. M. 2005: Mammal Species of the World. A Taxonomic and Geographic Reference. 3rd Ed. Johns Hopkins University Press, Baltimore. 